\section{THE OCCLUSION OF GASES IN METALS.}

$\mathrm{N}$ Tuesday, November 12, the Faraday Society held a discussion on the above subject, attended by a very representative gathering of the various aspects of it, theoretical and experimental. After a foreword by the president, Sir R. Hadfield, on the great war, the discussion was opened by Prof. Alfred W.' Porter, who emphasised that the term "occlusion" includes, in reality, a number of phenomena: chemical combination, simple or compound solid solution, surface adsorption accompanying solution, surface condensation unaccompanied by solution, and inclusion of gas forming blowholes visible to the naked eye or microscope. The difficulty of distinguishing between these several types was illustrated by the case of the occlusion of hydrogen by palladium, the nature of which, even at the present day, is still an unsettled problem. Amongst phenomena due to occlusion are the passivity of iron and the associated fact of the embrittling of iron by caustic soda. But there are other phenomena of more theoretical interest, such as the Volta effect, which has often been attributed to condensed layers of gases. By the experiments of $\mathrm{O}$. W. Richardson and of Langmuir on thermionic emissivity, the question of the origin of the Volta effect has been completely reopened.

In connection with the brittleness associated with occlusion in iron and other metals, the opener endeavoured to elicit an expression of opinion as to the nature of brittleness, illustrating his remarks with the well-known behaviour of cobbler's wax, which is exceedingly plastic under the action of small forces of long duration, but is as brittle as glass when struck a sharp blow. He laid stress on the necessity for paying attention to the time element in specifying brittleness.

Mr. Cosmo Johns followed on the technical side with a paper on the properties of metals as affected by their occluded gases. He distinguished between gases which are absorbed as such and those which are formed as a result of reactions between non-gaseous constituents during the cooling of the metals in question. It is known that molten copper and iron dissolve more hydrogen than when those metals are solid. A molten mass saturated with hydrogen at a particular partial pressure will, during freezing, become supersaturated with the gas. Some of this must be entrapped between the growing crystals and exist as macroscopic or microscopic gas enclosures, though this is probably not the only method by which occlusion occurs. Probably it is the inter-crystalline, amorphous matter that is chiefly concerned, and brittleness will be due to the change in this produced by the gas. He attributed the $\mathrm{CO}_{3}$ and $\mathrm{CO}$ occluded to reactions between dissolved oxide of iron and the carbon in the steel at the particular temperature when iron oxide, being thrown out of solution as freezing progresses, becomes concentrated in the mother-liquor between the growing crystals and reacts with the carbon which has not suffered the same concentration. He urged that all our knowledge of the properties of metals merely relates to metals containing occluded gases, and not to pure metals themselves.

Dr. Thomas Baker gave a description of experiments made to discover the relation, if any, between the temperature of evolution of gas and the critical points of steel. He finds that with hard steels the evolution of hydrogen reaches a maximum rate at $600^{\circ} \mathrm{C}$., and below this temperature constitutes the greater part of the gas, given off. Carbon monoxide is slowly evolved from the beginning, and reaches its maximum rate at $688^{\circ} \mathrm{C}$. With soft steel there is a further point of maximum evolution of hydrogen and carbon monoxide at $786^{\circ} \mathrm{C}$.

$$
\text { NO. } 2560 \text {, VOL. IO2] }
$$

Dr. McCance spoke on the balanced reactions in steel manufacture, particularly with reference to the open-hearth process. Dr. Hatfield pointed out the large influence which silicon has upon occlusion.

Dr. Rosenhain emphasised that all liquids are brittle, but, as the opener afterwards pointed out, it would be better to say all bodies. Mr. C. V. Boys, referring to the spitting of silver on solidification, stated that he had found that to avoid loss of silver through spitting in cupellation it was necessary to cool it very slowly; and he asked if this was due to the evolution taking place over a range of temperature, and not all precisely at the solidification point. It could not be due to differences of temperature in the solidifying mass, because a considerable amount of undercooling takes place, and the solidification, when it occurs, is a very rapid process, the whole mass rising practically instantaneously to the meltingpoint.

Sir T. K. Rose dealt with the bearing of Le Chatelier's princiole upon the change of the concentration of dissolved gases with temperature. Prof. N. T. M. Wilsmore pointed out that he had recently observed that the diminution of solubility of gases with rise of temperature, so far as data so, is peculiar to water as solvent, and that, even in the case of water, there seems to be a minimum at a moderate temperature (see the data in the last edition of Landolt-Börnstein). This important observation is quite contrary to the belief usually held. The exceptional character of water may be attributed to the variation in its degree of association.

Prof. H. E. Armstrong laid stress on the artificiality of distinguishing dissolution from combination; dissolution is combination.

Dr. R. E. Slade directed attention to the bearing of the eutectic point of $\mathrm{Ag}-\mathrm{Ag}_{2} \mathrm{O}$ at about $6^{\circ}$ below the melting-point of silver; and Drs. Harker and Rayner described interesting experiments with very large masses of molten silver.

Dr. Gwyer was in doubt as to the reason for the proportionality of solubility in some cases to the square root of the pressure, apparently omitting to notice the bearing of the Nernst-van't Hoff law of distribution when the molecular association is different in the free and dissolved states.

Many other interesting points were made by various speakers. The openers reserved their detailed replies to the printed discussion, where these points will be dealt with.

\section{GEOLOGY OF THE PERSIAN OILFIELDS.}

$A \mathrm{~N}$ interesting paper on the geology of the Persian A cilfields by Messrs. H, G. Busk and $H$. T. Mayo was read at the meeting of the Institution of Petroleum Technologists on October ${ }^{\text {15. Three areas }}$ are treated: the Bakhtiari country, in which the only oilfield worked as yet is situated; the Ahwaz-Pusht-iKuh country; and the Qishm Island and Persian Gulf region. The first of these is described in most detail. The rocks are divided into three series: The Asmari, Eo-cretaceous, at the base consists of massive limestones $2000 \mathrm{ft}$. or more in thickness. It is succeeded by the Miocene Fars series, more than $7000 \mathrm{ft}$. thick, divided into three groups: the lower, formed of some $3500 \mathrm{ft}$. of massive gypsum, shales, clays, and intercalated beds of detrital limestone; the middle, rooo $\mathrm{ft}$. of clays, shales, intercalated gypsum, limestone, and sandstone; and the upper, $2700 \mathrm{ft}$. of clays, shales, and intercalated red and brown sandstones. The Fars series is overlaid by the Bakhtiari series of Pliocene age, of which the lower group, 
${ }_{13}, 000 \mathrm{ft}$. or more of clays, sandstone, and conglomerate, is regarded as of lacustrine origin; and the upper, $2000 \mathrm{ft}$. of massive conglomerates, as torrential. The oil is found in the lower Fars group, the detrital limestones forming the reservoir; at Maidan-i-Naftun the wells all flow under strong pressure, and after ten years of remarkable production show no signs of exhaustion.

The geological history of the region seems to be one of extraordinary interest. The strata, from the base to the top of the Fars series, were deposited in a quiescent basin, and the thickness of beds between different horizons remains very constant. At the close of the Fars period folding began; the strata were thrown into open folds, and the overlying Bakhtiari series varies greatly in thickness, being thickest in the synclines, and least over the anticlines; towards the close of the period the synclines became filled up with sediment, and the upper Bakhtiari conglomerates spread over the whole. Then, according to the authors, a series of earth movements set in, continuing to the present and giving rise to a very complicated series of structures; fan, or, as they call it, Omega, structure was developed, and a series of thrust-faults which came right up to the surface and were partly determined by accidents of surface relief. In some cases the folds are completely overlaid by one overthrust extending beyond the next, and at Maidan-i-Naftun this is said to have been prevented only by the action of the Karun River, which flows for some miles in a gorge $800 \mathrm{ft}$. deep between the Tembi thrust-fault, which hades towards the oilfield on one side, and the back fault of the next fold, which hades in the opposite direction. The authors believe, in short, that the faulting and folding of this region were not only superficial, but also of recent date and continued, with a gradual relaxation, to the present day; they regard the surface features as largely due to the movements caused, to some extent, as determining this faulting, and consider that the advancing fronts of the overthrust blocks have been worn away by surface denudation, concomitantly with their advance by the action of the tectonic processes.

The Ahwaz-Pusht-i-Kuh region presents much the same features, with less intense disturbance; but in Qishm Island the identification of the rock series with that of the Bakhtiari country is doubtful, and the structure is very different, the rocks being disposed in a series of gentle domes along an axis running through the length of the island, these domes being subsidiary to a larger dome, exposing an inlier of the Eocene Hormuz series. Four explanations of this dome are discussed: that it is due to the intersection of two open folds of different dates, that it is of the same nature as the salt domes of Texas, that it is due to a laccolitic intrusion, and that it is due to the compression of the softer Miocene strata against a pre-existing boss of Eocene, round and against which they were deposited. No opinion is offered as to the relative probability of these, but the general features seem more in consonance with some cause analogous to the second and third, though the material to which the local uplift was due may have been neither salt nor a plutonic intrusion. Neither this nor the AhwazPusht-i-Kuh district has proved oil-bearing in a commercial sense. though indications have been found and both are being tested.

We may express a hope that, the absolute embargo on publication having been lifted, more of the large amount of geological information which is in possession of the Anglo-Persian Oil Co. and of the Indian Government may be made accessible. There can be no commercial reason for secrecy, as the company has a monopoly of the whole country, and the political reasons have been largely, and may soon be completely, removed. The value of publication will be great, as the region is one of extraordinary interest both in its structural aspect and as regards its bearirs on the principles which underlie the origin and distribution of petroleum.

\section{THE CONSTITUTION OF THE EARTH'S INTERIOR. $^{1}$}

THE problems of the interior of the earth are primarily of a physical character, and, in the final appeal, only to be decided by mathematical treatment; but this, in its turn, must be based on observation, and, therefore, it comes that this discussion is prefaced by a statement of the results which have been obtained by the sciences of observation. The preparation of this statement is simplified by the fact that the problems fall naturally into two tolerably distinct groups: (I) those relating to the outermost layer, amounting at most to I per cent. of the radius, and $(2)$ those of the deeper portions, extending to the centre.

The latter may be taken first. Records of the transmission of mass waves set up in connection with earthquakes show two well-marked groups representing two forms of wave-motion, presumably the longitudinal and transverse, and a steady increase of the rate of transmission, with no very marked break in regularity, up to a distance of about $120^{\circ}$ from the origin. Beyond that the first phase, of longitudinal waves, shows a decrease in velocity, and the second phase, of transverse waves, which, though so conspicuous at lesser distances, are no longer represented in their typical form, but are replaced by a record of different character, probably not due to any form of wave which has followed the direct path from the origin, and markedly delayed from the time at which they should have arrived had the same relative rate of propagation been maintained as at lesser distances. The depth reached by waves emerging at $120^{\circ}$ from the origin is about half the radius from the centre of the earth, and the conclusion to be drawn is that down to that depth the material of which the earth is composed is sufficiently rigid against stresses of short duration, and sufficiently isotropic to permit the transmission of the two forms of elastic waves and to give rise to their separation by reason of the different rates of travel. Further, it seems that down to a depth of half the radius there is no marked change in the character of the material, but at greater depths there is a change in physical character to a material, or form of matter, which is no longer able to transmit the distortional waves, or, if capable, can only do so with a great diminution of intensity and at about half the rate in the lower lavers of the outer shell; in other words, the material in the central nucleus has a very low degree of rigidity, even against stresses of only a few seconds' duration. The limit between the central nucleus and outer shell lies between four-tenths and five-tenths of the radius, measured from the centre of the earth; the transition between the two is apparently gradual, and not sufficiently abrupt to give rise to reffection of the waves at the iunction of the two.

Turning to the outer lavers, we have, next the surface, partly material which has been disintegrated bv the processes of surface denudation, transported, deposited, and resolidified, and partly rock which has not undergone these processes, but is thoroughly cooled and solid in every sense of the word. 'These

1 Synopsis of the opening of a discussion at a meeting of the British Assnciation Geophysical Committee on November 19 , by $R$. D. Oldham, F.R.S. 